\title{
Brood Reduction and Optimal Parental Investment when Offspring Differ in Quality
}

\section{Citation}

Haig, David. 1990. Brood reduction and optimal parental investment when offspring differ in quality. American Naturalist 136(4): 550-556.

\section{Published Version}

http://dx.doi.org/10.1086/285113

\section{Permanent link}

http://nrs.harvard.edu/urn-3:HUL.InstRepos:3153310

\section{Terms of Use}

This article was downloaded from Harvard University's DASH repository, and is made available under the terms and conditions applicable to Other Posted Material, as set forth at http:// nrs.harvard.edu/urn-3:HUL.InstRepos:dash.current.terms-of-use\#LAA

\section{Share Your Story}

The Harvard community has made this article openly available.

Please share how this access benefits you. Submit a story.

Accessibility 


\title{
CHICAgO JOURNALS
}

\section{The American Society of Naturalists}

\author{
Brood Reduction and Optimal Parental Investment when Offspring Differ in Quality \\ Author(s): David Haig \\ Source: The American Naturalist, Vol. 136, No. 4 (Oct., 1990), pp. 550-556 \\ Published by: The University of Chicago Press for The American Society of Naturalists \\ Stable URL: http://www.jstor.org/stable/2462194
}

Accessed: 15/05/2009 11:55

Your use of the JSTOR archive indicates your acceptance of JSTOR's Terms and Conditions of Use, available at http://www.jstor.org/page/info/about/policies/terms.jsp. JSTOR's Terms and Conditions of Use provides, in part, that unless you have obtained prior permission, you may not download an entire issue of a journal or multiple copies of articles, and you may use content in the JSTOR archive only for your personal, non-commercial use.

Please contact the publisher regarding any further use of this work. Publisher contact information may be obtained at http://www.jstor.org/action/showPublisher?publisherCode=ucpress.

Each copy of any part of a JSTOR transmission must contain the same copyright notice that appears on the screen or printed page of such transmission.

JSTOR is a not-for-profit organization founded in 1995 to build trusted digital archives for scholarship. We work with the scholarly community to preserve their work and the materials they rely upon, and to build a common research platform that promotes the discovery and use of these resources. For more information about JSTOR, please contact support@ jstor.org. 


\section{BROOD REDUCTION AND OPTIMAL PARENTAL INVESTMENT WHEN OFFSPRING DIFFER IN QUALITY}

Any parent has finite amounts of resources available for reproduction. The more resources supplied to an offspring, the greater should be the offspring's chances of survival and future reproduction, but the fewer resources should remain for the parent to produce other offspring. Thus, a parent could invest a small amount in each of a large number of inexpensive offspring or a large amount in each of a smaller number of offspring. Smith and Fretwell (1974) developed a simple graphic model of the selective consequences of different resource allocations among offspring. They assumed that parental investment could be represented as a single quantity and that an offspring's fitness could be expressed as a function of the investment received. Parental fitness, for a given allocation, was defined as the return in offspring fitness per unit of investment. This corresponds to the slope of a line from the origin to the appropriate point on the function. The tangent to the curve through the origin had the steepest gradient and gave the allocation to individual offspring that maximized parental fitness. Their model has been widely used and was recently formalized by Lloyd (1987).

Smith and Fretwell's model predicts that an optimal parent should invest the same amount in each offspring. However, the model assumes that the function relating offspring fitness to parental investment is the same for all offspring; more precisely, the model assumes that a parent cannot detect differences in offspring quality before resources are committed. Temme (1986) argued that equal investment does not maximize parental fitness if offspring differ in quality. Rather, the parent should invest different amounts in offspring of different quality, such that the marginal return from additional investment would be the same for all offspring.

In this note, I extend Temme's argument by deriving the optimal parental investment for different relative frequencies of offspring types. I also consider when it is in a parent's interests to abort rather than provision offspring of lower quality. My model addresses a basic question: how should a parent allocate resources among offspring when the offspring have different expectations of fitness given the same parental investment? The answer is simple. Parental resources are optimally distributed when (1) the marginal return from each provisioned offspring equals the average return from all offspring, and (2) offspring whose quality falls below some threshold are aborted and yield no return on their cost. 


\section{THE MODEL}

The model presented below assumes that the number of offspring produced by a parent is determined by the parent's allocation to individual offspring and the size of the resource pool. A change in a parent's allocation strategy or a change in total allocation results in a change in the number of offspring. Changes in allocation strategy are assumed to be without direct cost to the parent, but different strategies may give different returns on investment. Three assumptions are made about the function relating offspring fitness to parental investment: (1) there is some minimum investment below which an offspring has zero fitness; (2) offspring fitness is an increasing function of parental investment; and (3) the function is convex (i.e., there are diminishing marginal returns). All these assumptions are either implicit or explicit in the models of Smith and Fretwell (1974) and Temme (1986). In my model, a parent cannot vary the proportion of offspring of a given quality but can adjust the amount invested in individual offspring of different quality.

Suppose that offspring belong to two types, A and B, with relative frequencies $p$ and $1-p$. A parent invests an amount $a$ in each A offspring and $b$ in each B offspring. Each offspring makes an independent contribution to parental fitness, and the offspring's contribution is a function of the resources that it receives. Differences in quality between $\mathrm{A}$ and $\mathrm{B}$ offspring are expressed as different functions, $f_{\mathrm{A}}(a)$ and $f_{\mathrm{B}}(b)$. Parental fitness, $w$, can be defined as the average return per unit of investment:

$$
w=\frac{p f_{\mathrm{A}}(a)+(1-p) f_{\mathrm{B}}(b)}{p a+(1-p) b} .
$$

By assumption of the model, $a$ and $b$ are subject to diminishing returns. If the marginal returns from $A$ and $B$ offspring are unequal, the parent could increase its average return (fitness) by allocating a little more to each offspring with the higher marginal return and a little less to each offspring with the lower marginal return. If the marginal returns are equal but less than the average return, the parent could increase its fitness by reducing the total number of offspring and allocating a little more to each offspring. Therefore, the optimal set of allocations $(\hat{a}, \hat{b})$ occurs when the marginal returns from investment in each type is equal to the average return per unit of investment. That is,

$$
\begin{aligned}
& \hat{w}=f_{\mathrm{A}}^{\prime}(\hat{a})=f_{\mathrm{B}}^{\prime}(\hat{b}), \\
& \hat{w}=\frac{p f_{\mathrm{A}}(\hat{a})+(1-p) f_{\mathrm{B}}(\hat{b})}{p \hat{a}+(1-p) \hat{b}} .
\end{aligned}
$$

The values of $\hat{a}$ and $\hat{b}$ depend on $p$. The model's behavior can be examined by considering the extreme conditions when $p=1$ (all type $\mathrm{A}$ ),

$$
f_{\mathrm{A}}^{\prime}\left(a^{*}\right)=f_{\mathrm{A}}\left(a^{*}\right) / a^{*},
$$



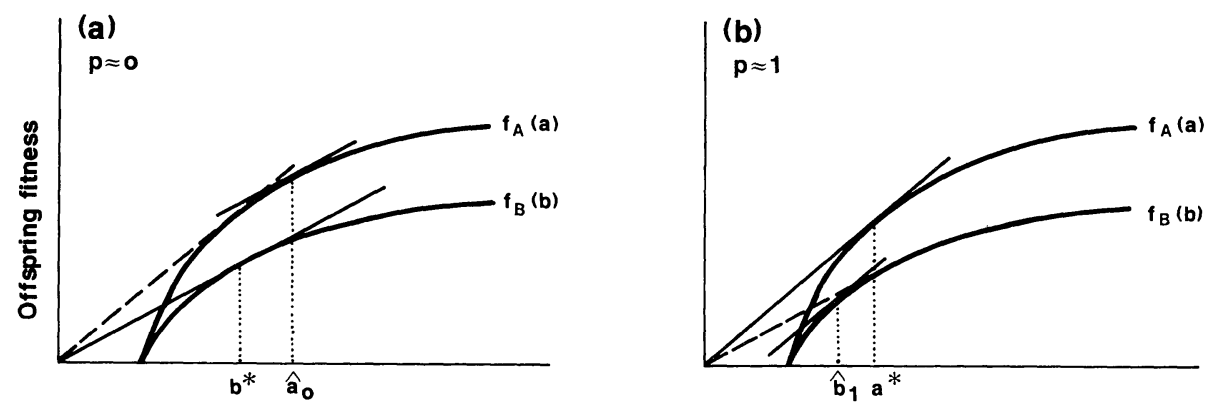

Parental investment $(a, b)$

Fig. 1.-The optimal parental investment in type-A and type-B offspring is given by the intercept of the solid tangent with the appropriate curve: view $a$, offspring predominantly of type B; view $b$, offspring predominantly of type A.

and when $p=0$ (all type $\mathrm{B})$,

$$
f_{\mathrm{B}}^{\prime}\left(b^{*}\right)=f_{\mathrm{B}}\left(b^{*}\right) / b^{*} .
$$

The allocations $a^{*}$ and $b^{*}$ are the Smith-Fretwell allocations for A and B offspring, respectively. Suppose that, for an equivalent investment, A offspring have superior fitness to $\mathrm{B}$ offspring. If a parent produces predominantly $\mathrm{B}$ offspring $(p \approx 0)$, each $\mathrm{B}$ offspring should receive $b^{*}$, and the rare A offspring should receive $\hat{a}_{0}$ such that $f_{\mathrm{A}}^{\prime}\left(\hat{a}_{0}\right)=f_{\mathrm{B}}\left(b^{*}\right) / b^{*}$ (fig. $\left.1 a\right)$. The optimal allocation to each $\mathrm{A}$ offspring will be greater than $a^{*}$. As the proportion of A offspring increases, $\hat{a}$ approaches $a^{*}$, and $\hat{b}$ decreases below $b^{*}$. If the parent produces predominantly A offspring $(p \approx 1)$, each $\mathrm{A}$ offspring should receive $a^{*}$, and the rare $\mathrm{B}$ offspring should receive $\hat{b}_{1}$, such that $f_{\mathrm{B}}^{\prime}\left(\hat{b}_{1}\right)=f_{\mathrm{A}}\left(a^{*}\right) / a^{*}$ (fig. $1 b$ ). The greater the proportion of $\mathrm{A}$ offspring, the greater is parental fitness at the optimal strategy and the smaller is the investment by the parent in individual offspring of either type.

Temme (1986) similarly assumed equal marginal returns from investment in both types, but he did not consider variation in the proportion of offspring belonging to each type. The dependence of optimal allocation on $p$ is easily explained. If $\mathrm{A}$ offspring are more common, the parent can achieve a higher average return. Therefore, marginal returns from individual offspring of both types will be greater (because marginal returns equal average returns for the optimal strategy), and the allocation to individual offspring of both types will be less (because of diminishing marginal returns).

The model can be extended to consider selective brood reduction. Suppose that the parent aborts all $\mathrm{B}$ offspring at some cost $c$ per aborted offspring; then,

$$
w=\frac{p f_{\mathrm{A}}(a)}{p a+(1-p) c} .
$$

The optimal investment in A offspring when B offspring are aborted, $\tilde{a}$, occurs 


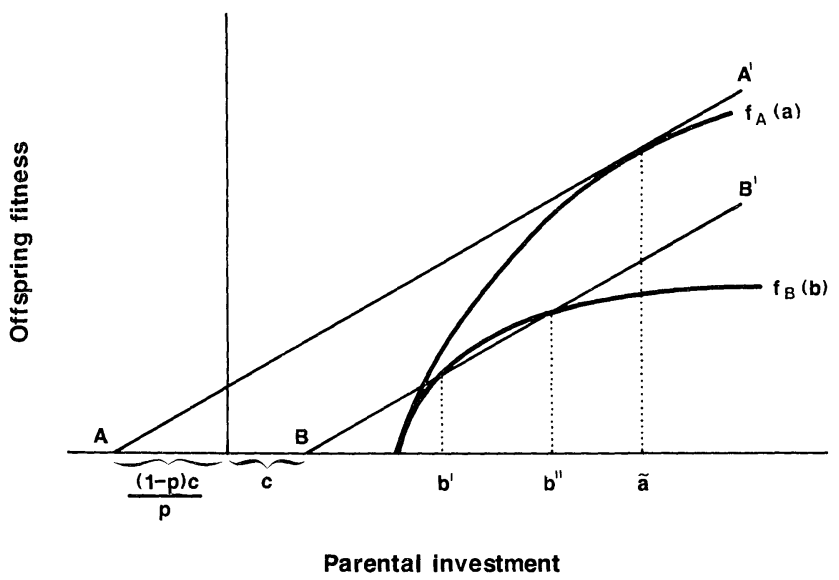

FIG. 2.-The optimal parental investment in A offspring when B offspring are aborted is given by the intercept of the tangent $\mathrm{AA}^{\prime}$ with $f_{\mathrm{A}}(a)$. The proportion of $\mathrm{A}$ offspring is $p$, and the cost of aborting a $\mathrm{B}$ offspring is $c$. A strategy in which $\mathrm{B}$ offspring are provisioned is superior to the abortion strategy if the line $\mathrm{BB}^{\prime}$ (parallel to $\mathrm{AA}^{\prime}$ ) intersects $f_{\mathrm{B}}(b)$ (see the text).

when marginal returns equal the average return:

$$
\tilde{w}=f_{\mathrm{A}}^{\prime}(\tilde{a})=\frac{p f_{\mathrm{A}}(\tilde{a})}{p \tilde{a}+(1-p) c} .
$$

The optimal strategy is represented graphically in figure 2 . The line $\mathrm{AA}^{\prime}$ is the tangent to $f_{\mathrm{A}}(a)$ drawn from the point $(1-p) c / p$ to the left of the origin. The point at which this tangent touches the fitness function defines $\tilde{a}$. The result is the same as that of the Smith-Fretwell model for A offspring except that an additional cost $(1-p) c / p$ is associated with each A offspring. The factor $(1-p) / p$ is the number of aborted B offspring per provisioned A offspring.

Suppose that a parent provisions each A offspring with $\tilde{a}$. The parent can achieve equivalent fitness by aborting B offspring at cost $c$ or by provisioning B offspring with amount $b$ if

$$
\frac{p f_{\mathrm{A}}(\tilde{a})}{p \tilde{a}+(1-p) c}=\frac{p f_{\mathrm{A}}(\tilde{a})+(1-p) f_{\mathrm{B}}(b)}{p \tilde{a}+(1-p) b},
$$

which simplifies to

$$
\frac{p f_{\mathrm{A}}(\tilde{a})}{p \tilde{a}+(1-p) c}=\frac{f_{\mathrm{B}}(b)}{b-c} \text {. }
$$

This result has the intuitive interpretation shown in figure 2. The left-hand side of equation (5b) is the average return per unit of investment for the best abortion strategy. This is represented by the slope of the line $\mathrm{AA}^{\prime}$. The right-hand side of 
equation (5b) is the average return on that portion of investment in $B$ that is in excess of the fixed cost $c$. $\mathrm{BB}^{\prime}$ is the line, parallel to $\mathrm{AA}^{\prime}$, that cuts the horizontal axis at the point $c$. The right-hand side of equation (5b) equals the left-hand side at $b^{\prime}$ and $b^{\prime \prime}$ where $\mathrm{BB}^{\prime}$ cuts $f_{\mathrm{B}}(b)$. Since this function is convex (by the assumption of diminishing returns), the parent could achieve higher fitness by investing $b$ between $b^{\prime}$ and $b^{\prime \prime}$. Therefore, there exist allocations $\hat{a}$ and $\hat{b}$ that give greater average returns than the abortion strategy. If $\mathrm{BB}^{\prime}$ did not intersect $f_{\mathrm{B}}(b)$, then the abortion strategy would be superior to any strategy in which $B$ offspring were provisioned. The distance between the horizontal intercepts of $\mathrm{AA}^{\prime}$ and $\mathrm{BB}^{\prime}$ is $c / p$ $(=[1-p] c / p+c)$. The smaller the value of $c / p$, the smaller the difference in quality between $\mathrm{A}$ and $\mathrm{B}$ offspring that would favor the abortion of the lowerquality type.

The model's overall dynamics can be summarized. As $p$ (the proportion of higher-quality A offspring) increases, the optimal allocations, $\hat{a}$ and $\hat{b}$, decrease. Above some threshold value of $p$, the parent's optimal strategy is to abort $\mathrm{B}$ offspring at cost $c$. If $\mathrm{B}$ offspring are aborted, increases in $p$ continue to decrease $\hat{a}$ because this reduces the cost of abortion per A offspring (i.e., reduces $[1-p]$ • $c / p$ ). At the limit (when $p=1$ ), $\hat{a}$ equals the Smith-Fretwell allocation $a^{*}$. For given $f_{\mathrm{A}}(a)$ and $f_{\mathrm{B}}(b)$, the smaller the value of $c$, the smaller is the threshold value of $p$.

The model presented here is a specific case of the economic principle that a profit-maximizing firm tends to equalize the ratio of marginal product over cost for all activities (see Bloom et al. 1985; Lloyd 1988; any economics text). This principle defines both the optimal parental allocation among offspring of different quality and the optimal time spent foraging in patches of different quality. In both cases, an individual attempts to maximize the return (fitness or energy) from an investment (resources or time) in units (offspring or patches) of different quality. There is a strict analogy between Charnov's (1976) conclusion that an optimal predator should abandon a patch once the marginal capture rate drops to the average capture rate for the habitat and my conclusion that an optimal parent should terminate investment in an offspring once the marginal return falls to the average return from all offspring.

Because of the close analogy to optimal-foraging theory, theorems about foraging can be translated into theorems about parental allocation. Arditi and Dacorogna (1988) have developed an elegant model of optimal foraging in a onedimensional environment with an arbitrary food distribution. In their model, a forager moves through the environment, adjusting its speed to the local availability of food. The slower the forager's movement, the greater the investment of time in foraging. The optimal strategy is to move at the maximal rate (without foraging) through areas with food availability below some threshold and to slow down in areas above the threshold so as to reduce local food availability to the threshold. Their model can be translated into a statement about parental allocation for an arbitrary distribution of offspring quality. Successive offspring of a parent can be represented as contiguous patches encountered by a forager. Aborted offspring are patches below the threshold, and the cost of abortion is the time spent in such patches. A parent's optimal strategy is to abort all offspring whose quality falls 
below some threshold and to provision each remaining offspring until the marginal return from investment equals the average return.

\section{DISCUSSION}

In a metaphorical sense, a parent can be said to possess information about its expected reproductive success from alternative allocation strategies. The source of this information is natural selection: the differential reproductive success of parents employing different strategies under similar circumstances. The precision of adaptation is related to the quality of information, that is, to the number of different circumstances recognized by the parent in determining allocation. The classic Smith-Fretwell model corresponds to the case in which a parent has information about the average relation between offspring fitness and amount invested but has no information about (i.e., does not recognize) differences among offspring. The parent's optimal strategy is to invest the same amount in each offspring (Smith and Fretwell 1974).

Offspring differ in quality to the extent that they have different expected fitnesses given the same parental investment. Temme (1986) and I have shown that equal investment does not maximize parental fitness if a parent can detect differences in offspring quality. Rather, a parent should equalize the expected marginal returns from all provisioned offspring. As a result, some offspring should receive more resources than others. The "expected fitnesses" and "expected marginal returns" are the expectations given the information available to the parent. A parent might recognize only broad categories of offspring (e.g., offspring with gross developmental abnormalities vs. normal offspring; male vs. female) or might be able to make finer distinctions.

Variation in quality is not necessarily genotypic. Thus, seeds produced late in the season are often smaller than seeds produced early in the season (Cavers and Steel 1984). A possible explanation is that late seeds have lower expected fitness than early seeds given the same parental investment. Other explanations are possible (McGinley and Charnov 1988), but the hypothesis does make testable predictions about the relative success of seeds sown at different times.

Brood reduction is an extreme case of differential investment. Lloyd (1987) demonstrated that brood reduction may be adaptive if total reproductive allocation is uncertain when offspring number is being determined. This note demonstrates that brood reduction may also be adaptive if offspring differ in quality. My model identifies when it is in a parent's interests to abort rather than provision offspring of lower quality. This formalizes the hypothesis that selective brood reduction can enhance parental fitness if abortion occurs before substantial resources are committed to offspring (for recent discussions of this hypothesis, see Queller 1987; Stearns 1987).

\section{ACKNOWLEDGMENTS}

I thank D. Temme, M. Westoby, and the anonymous reviewers for helpful comments on an earlier version of the manuscript. 


\author{
LITERATURE CITED
}

Arditi, R., and B. Dacorogna. 1988. Optimal foraging on arbitrary food distributions and the definition of habitat patches. Am. Nat. 131:837-846.

Bloom, A. J., F. S. Chapin, and H. A. Mooney. 1985. Resource limitation in plants-an economic analogy. Annu. Rev. Ecol. Syst. 16:363-392.

Cavers, P. B., and M. G. Steel. 1984. Patterns of change in seed weight over time on individual plants. Am. Nat. 124:324-335.

Charnov, E. L. 1976. Optimal foraging, the marginal value theorem. Theor. Popul. Biol. 9:129-136.

Lloyd, D. G. 1987. Selection of offspring size at independence and other size-versus-number strategies. Am. Nat. 129:800-817.

1988. A general principle for the allocation of limited resources. Evol. Ecol. 2:175-187.

McGinley, M. A., and E. L. Charnov. 1988. Multiple resources and the optimal balance between size and number of offspring. Evol. Ecol. 2:77-84.

Queller, D. C. 1987. Sexual selection in flowering plants. Pages 165-179 in J. W. Bradbury and M. B. Andersson, eds. Sexual selection: testing the alternatives. Wiley, New York.

Smith, C. C., and S. D. Fretwell. 1974. The optimal balance between size and number of offspring. Am. Nat. 108:499-506.

Stearns, S. C. 1987. The selection-arena hypothesis. Pages 337-380 in S. C. Stearns, ed. The evolution of sex and its consequences. Birkhäuser, Basel.

Temme, D. H. 1986. Seed size variability: a consequence of variable genetic quality among offspring? Evolution 40:414-417.

\title{
School of Biological Sciences \\ MACQUARIE UNIVERSITY \\ New South Wales 2 IO9 \\ Australia \\ Submitted February 21, 1989; Accepted August 1, 1989
}

*Present address: Department of Plant Sciences, South Parks Road, Oxford OX1 3RA, England. 